BMJ Open

Diabetes

Research

$\&$ Care

\section{Anthropometric cut-offs to identify hyperglycemia in an Afro-Caribbean population: a cross-sectional population-based study from Barbados}

To cite: Wade AN, Hambleton IR, Hennis AJM, et al. Anthropometric cut-offs to identify hyperglycemia in an Afro-Caribbean population: a cross-sectional populationbased study from Barbados. BMJ Open Diab Res Care 2021;9:e002246. doi:10.1136/ bmjdrc-2021-002246

Received 28 February 2021 Accepted 27 July 2021
Check for updates

\section{(C) Author(s) (or their} employer(s)) 2021. Re-use permitted under CC BY-NC. No commercial re-use. See rights and permissions. Published by BMJ.

For numbered affiliations see end of article.

Correspondence to Professor Nigel Unwin; n.unwin2@exeter.ac.uk

\section{ABSTRACT}

Introduction Body mass index (BMI) and waist circumference (WC) cut-offs associated with

hyperglycemia may differ by ethnicity. We investigated the optimal BMI and WC cut-offs for identifying hyperglycemia in the predominantly Afro-Caribbean population of Barbados.

Research design and methods A cross-sectional study of 865 individuals aged $\geq 25$ years without known diabetes or cardiovascular disease was conducted. Hyperglycemia was defined as fasting plasma glucose $\geq 5.6 \mathrm{mmol} / \mathrm{L}$ or hemoglobin $A_{1 c} \geq 5.7 \%(39 \mathrm{mmol} / \mathrm{mol})$. The Youden index was used to identify the optimal cut-offs from the receiver operating characteristic (ROC) curves. Further ROC analysis and multivariable log binomial regression were used to compare standard and data-derived cut-offs.

Results The prevalence of hyperglycemia was $58.9 \%$ (95\% Cl $54.7 \%$ to $63.0 \%$ ). In women, optimal BMl and WC cut-offs $\left(27 \mathrm{~kg} / \mathrm{m}^{2}\right.$ and $87 \mathrm{~cm}$, respectively) performed similarly to standard cut-offs. In men, sensitivities of the optimal cut-offs of BMl $\geq 24 \mathrm{~kg} / \mathrm{m}^{2}(72.0 \%)$ and WC $\geq 86 \mathrm{~cm}$ $(74.0 \%)$ were higher than those for standard BMI and WC obesity cut-offs ( $30.0 \%$ and $25 \%-46 \%$, respectively), although with lower specificity. Hyperglycemia was $70 \%$ higher in men above the data-derived WC cut-off (prevalence ratio $95 \% \mathrm{Cl} 1.2$ to 2.3 ).

Conclusions While BMI and WC cut-offs in Afro-Caribbean women approximate international standards, our findings, consistent with other studies, suggest lowering cutoffs in men may be warranted to improve detection of hyperglycemia. Our findings do, however, require replication in a new data set.

\section{INTRODUCTION}

Diabetes is a leading cause of morbidity and mortality worldwide ${ }^{12}$ and the Englishspeaking Caribbean subregion of the Americas is no exception. In 2016, mortality from diabetes mellitus in these countries was nearly twice the regional average (64.9 vs 33.5 per $100000),{ }^{3}$ and Afro-Caribbean ancestry is recognized as a risk factor for the development of diabetes. ${ }^{4}$ The impact of diabetes on the small economies of Caribbean countries is significant-in four Caribbean countries,

\section{Significance of this study}

What is already known about this subject?

- Body mass index and waist circumference cutoffs associated with hyperglycemia may differ by ethnicity.

What are the new findings?

- Standard definitions of generalized and abdominal obesity have poor sensitivity in detecting prevalent hyperglycemia in Afro-Caribbean men.

- The population-specific body mass index and waist circumference thresholds for optimally detecting hyperglycemia in Afro-Caribbean men are, at $24 \mathrm{~kg} / \mathrm{m}^{2}$ and $86 \mathrm{~cm}$ respectively, lower than standard obesity definitions.

How might these results change the focus of research or clinical practice?

- Modifying obesity definitions in Afro-Caribbean men may be warranted to improve detection of hyperglycemia.

the economic cost of diabetes, combined with hypertension, was estimated to be between $1 \%$ and $8 \%$ of gross domestic product. ${ }^{5}$ While policy interventions which successfully target unhealthy behaviors can reduce population risk, ${ }^{6}$ identifying individuals with undiagnosed diabetes and those with intermediate hyperglycemia or pre-diabetes, who are at higher risk of developing diabetes and would benefit from intervention, is also an effective and necessary strategy to decrease diabetes morbidity and mortality. ${ }^{7}$

Widespread biochemical testing for diabetes in the Caribbean is, however, impractical and risk factors which can be easily assessed are essential to developing a cost-effective screening strategy. While international guidelines identify excess weight as one such risk factor for type 2 diabetes, ${ }^{4}$ existing data suggest that associations between adiposity 
and hyperglycemic risk differ by ethnicity. ${ }^{8}$ Consequently, widely accepted anthropometric cut-offs for overweight and obesity, whether based on body mass index (BMI) or waist circumference (WC), may not, in fact, identify AfroCaribbean individuals who are at higher risk of hyperglycemia. Appropriately defined BMI and WC cut-offs remain, however, potentially inexpensive, simply implemented strategies for identifying individuals who would benefit from further investigation and additional work in this area is therefore necessary.

Our objective, using the approach adopted in other studies, ${ }^{910}$ was to investigate the optimal BMI and WC cutoffs for discriminating between those with and without hyperglycemia on the Caribbean island of Barbados, which has a high prevalence of pre-diabetes, diabetes and diabetes-related complications. ${ }^{11-14}$ We compared population-specific and international standard cutoffs and hypothesized that the population-specific cutoffs would have better performance characteristics in detecting individuals likely to have undiagnosed hyperglycemia (pre-diabetes and diabetes) and thus requiring further evaluation. In addition, our findings might inform the definition of optimal anthropometric indices in this population and in similar populations of primarily African descent.

\section{RESEARCH DESIGN AND METHODS}

The survey methodology has been described in detail elsewhere. ${ }^{11} 14$ In brief, a cross-sectional survey was undertaken between September 2011 and May 2013 in adults aged $\geq 25$ years in Barbados, an English-speaking country in the eastern Caribbean of approximately 280 000 individuals, $92.4 \%$ of whom are of African descent. Study data were collected by 11 fieldworkers who underwent training and accreditation sessions, which included ensuring that they followed the study's standard operating procedures for measurement of height, weight and waist circumference. The training sessions were repeated during the survey. In addition, each fieldworker had a minimum of three supervised visits before collecting data independently. Demographic, behavioral and medical history data were collected using the Pan-American modification of the WHO STEPwise Approach to NonCommunicable Disease Surveillance questionnaire. ${ }^{15}$ Anthropometric and clinical measurements for a given study participant, including weight, standing height and WC, were performed by a single observer. WC was measured horizontally at the midpoint between the lower rib and the iliac crest in the mid-axillary line. Two initial measurements were taken, with a third measurement taken if the first two differed by more than $0.5 \mathrm{~cm}$, and the mean of the two closest measurements was used in the analysis. BMI was calculated as weight in kilograms divided by height in meters squared.

Venous blood samples were collected after a minimum 9-hour fast in sodium fluoride and EDTA tubes for glucose and hemoglobin $\mathrm{A}_{1 \mathrm{c}}\left(\mathrm{HbA}_{1 \mathrm{c}}\right)$ assays, respectively.

\section{Laboratory analysis}

Plasma glucose was assayed using a glucohexokinase method (Roche Cobas 6000, Roche Diagnostics, Mannheim, Germany) and $\mathrm{HbA}_{1 c}$ was assayed using a National Glycohemoglobin Standardization Program-traceable DCA 2000 analyzer (Siemens Healthcare Diagnostics, Munich, Germany). As described in detail elsewhere, ${ }^{14}$ $\mathrm{HbA}_{1 \mathrm{c}}$ analyses on 56 samples were performed using both the DCA 2000 analyzer and high-performance liquid chromatography at the American College of Pathologyaccredited Barbados Reference Laboratory, and a regression equation was developed to adjust the results from the DCA 2000 analyzer so they were comparable with those obtained at the national reference laboratory.

Written informed consent was obtained from all participants.

\section{Definitions}

\section{Anthropometric variables}

We used standard definitions, namely BMI $\geq 30 \mathrm{~kg} / \mathrm{m}^{2}$ for generalized obesity and BMI $\geq 25 \mathrm{~kg} / \mathrm{m}^{2}$ for generalized overweight and obesity. We used two different definitions for abdominal obesity: the International Diabetes Federation (IDF) definition of WC $\geq 80 \mathrm{~cm}$ in women and $94 \mathrm{~cm}$ in men ${ }^{16}$ and the American Heart Association/National Heart, Lung, and Blood Institute (AHA/NHLBI) modification of the Adult Treatment Panel III definition of $\mathrm{WC} \geq 88 \mathrm{~cm}$ in women and $102 \mathrm{~cm}$ in men. ${ }^{17}$

\section{Hyperglycemia}

We defined hyperglycemia using the American Diabetes Association (ADA) criteria of fasting plasma glucose $\geq 5.6 \mathrm{mmol} / \mathrm{L}$ or $\mathrm{HbA}_{1 \mathrm{c}} \geq 5.7 \%(39 \mathrm{mmol} / \mathrm{mol}) .{ }^{18}$ We performed sensitivity analyses using the WHO criteria of fasting plasma glucose $\geq 6.1 \mathrm{mmol} / \mathrm{L}$ or $\mathrm{HbA}_{1 \mathrm{c}} \geq 6 \%$ (42 $\mathrm{mmol} / \mathrm{mol}$ ).

\section{Statistical analysis}

As our aim was to identify those with undiagnosed prediabetes or diabetes, individuals who reported a previous diagnosis of diabetes were excluded from the analysis. We also excluded those who reported a previous diagnosis of vascular disease, such as stroke or ischemic heart disease, given that individuals with these conditions would require assessment of their glycemic status.

Weights were applied to account for the sampling design and non-response and to match the age and sex distribution of the Barbadian population according to the 2010 census. Full details of the weighting scheme are available online in appendix 1 of Howitt $e t$ al. ${ }^{11}$ Prevalence estimates with $95 \%$ CIs are presented overall and for subgroups defined by sex.

We used the same approach to investigating cut-offs as Ekoru et $a l^{9}{ }^{9}$ who investigated the appropriate WC cutoffs to identify metabolic risk in sub-Saharan African populations. The ability of BMI and WC to discriminate between those with and without hyperglycemia was summarized using the area under the curve (AUC) of 
the receiver operating characteristic (ROC) curves stratified by sex. The Youden index for the ROC curve for each anthropometric measurement was selected as the optimal data-derived cut-off. The sensitivity, specificity, positive predictive value and negative predictive value of both standard and data-derived cut-offs for BMI and WC in detecting hyperglycemia were then determined.

Log binomial regression models, adjusted for age, were fitted to investigate the strength of association (as adjusted prevalence ratios) between standard and dataderived cut-offs and hyperglycemia.

Data were analyzed using Stata statistical software (V.13).

\section{RESULTS}

Of the 1234 individuals recruited to the study, 226 had known diabetes and/or cardiovascular disease and were excluded from the analysis. A further 143 individuals were excluded due to missing data $(69.2 \%$ with missing fasting plasma glucose and/or $\mathrm{HbA}_{1 \mathrm{c}}$ and $30.8 \%$ with missing WC and/or BMI). Those excluded due to missing data did not differ in age from those who were included (mean age 46.7 years vs 46.8 years) but were more likely to be female $(\mathrm{p}=0.039)$.

Eight hundred and sixty-five participants were included in the analysis and their characteristics are shown in table 1 . The mean age (SD) of the weighted sample was 46.8 (14.8) years and $50.4 \%$ of the participants were female. All generalized and abdominal obesity indices were higher in women than in men. Over a quarter of the population had hyperglycemia based on the WHO criteria and over half based on the ADA criteria. The prevalence of total hyperglycemia was higher in women for both WHO and ADA criteria but $95 \%$ CIs were overlapping.

The ROC curves for BMI and WC, stratified by sex, are shown in figure 1 , and the performance characteristics of the standard and data-derived cut-offs for detecting ADAdefined hyperglycemia are shown in table 2. In women, the data-derived BMI cut-off of $27 \mathrm{~kg} / \mathrm{m}^{2}$ was intermediate

Table 1 Demographic, anthropometric and biochemical characteristics of participants

\begin{tabular}{|c|c|c|c|}
\hline & Women, $n=519(436)^{*}$ & Men, $n=346(429)^{*}$ & Overall, $n=865(865)^{*}$ \\
\hline Mean age (SD) (years) & $47.3(16.2)$ & $46.4(13.3)$ & $46.8(14.8)$ \\
\hline \multicolumn{4}{|l|}{ Number by age group in years } \\
\hline $25-44^{*}$ & $222(214)$ & $136(224)$ & $358(439)$ \\
\hline $45-64^{*}$ & $225(164)$ & $147(150)$ & $372(314)$ \\
\hline $65+^{*}$ & $72(57)$ & $63(55)$ & $135(113)$ \\
\hline \multicolumn{4}{|l|}{ Anthropometry } \\
\hline Mean BMI (SD) (kg/m²) & $29.8(8.2)$ & $26.4(4.6)$ & $28.1(6.7)$ \\
\hline Mean waist circumference (SD) $(\mathrm{cm})$ & $92.6(16.1)$ & $90.0(12.0)$ & $91.3(14.1)$ \\
\hline$\% \mathrm{BMl} \geq 25 \mathrm{~kg} / \mathrm{m}^{2}$ & 73.9 (69.1 to 78.3$)$ & 55.7 (48.3 to 62.8$)$ & $64.9(60.6$ to 68.9$)$ \\
\hline$\% \mathrm{BMI} \geq 30 \mathrm{~kg} / \mathrm{m}^{2}$ & $42.5(37.7$ to 47.4$)$ & $22.3(17.4$ to 28.1$)$ & 32.5 (28.8 to 36.4$)$ \\
\hline$\%$ IDF abdominal obesity & 80.1 (75.6 to 84.0$)$ & 35.0 (27.9 to 42.8$)$ & 57.7 (52.4 to 62.9) \\
\hline$\%$ AHA/NHLBI abdominal obesity & 58.6 (54.1 to 63.0$)$ & 18.0 (13.6 to 23.3$)$ & 38.4 (34.4 to 42.6$)$ \\
\hline \multicolumn{4}{|l|}{ Measures of glycemia } \\
\hline Mean fasting plasma glucose (SD) (mmol/L) & $5.3(1.4)$ & $5.2(0.8)$ & $5.3(1.1)$ \\
\hline Mean $\mathrm{HbA}_{1 \mathrm{c}}(\mathrm{SD})(\%)$ & $5.8(0.8)$ & $5.7(0.4)$ & $5.7(0.6)$ \\
\hline Mean $\mathrm{HbA}_{1 \mathrm{c}}(\mathrm{SD})(\mathrm{mmol} / \mathrm{mol})$ & $40(8.7)$ & $39(4.4)$ & $39(6.6)$ \\
\hline \multicolumn{4}{|l|}{ Hyperglycemia (ADA categories) } \\
\hline$\%$ fasting plasma glucose $\geq 5.6 \mathrm{mmol} / \mathrm{L}$ & 21.1 (16.8 to 26.2 ) & 22.6 (18.2 to 27.7$)$ & 21.9 (18.8 to 25.3$)$ \\
\hline$\% \mathrm{HbA}_{1 \mathrm{c}} \geq 5.7 \%(39 \mathrm{mmol} / \mathrm{mol})$ & 58.9 (54.6 to 63.0$)$ & 49.4 (42.9 to 55.9$)$ & $54.2(50.1$ to 58.1$)$ \\
\hline$\%$ total hyperglycemia & $63.5(59.2$ to 67.7$)$ & 54.3 (47.3 to 61.1$)$ & $58.9(54.7$ to 63.0$)$ \\
\hline \multicolumn{4}{|l|}{ Hyperglycemia (WHO categories) } \\
\hline$\%$ fasting plasma glucose $\geq 6.1 \mathrm{mmol} / \mathrm{L}$ & $9.8(6.8$ to 14.0$)$ & 9.8 (7.0 to 13.6$)$ & 9.8 (7.6 to 12.6$)$ \\
\hline$\% \mathrm{HbA}_{1 \mathrm{c}} \geq 6.0 \%(42 \mathrm{mmol} / \mathrm{mol})$ & 27.6 (23.2 to 32.5$)$ & 21.8 (17.6 to 26.5$)$ & 24.7 (21.6 to 28.1$)$ \\
\hline$\%$ total hyperglycemia & 29.7 (24.9 to 35.0$)$ & 25.2 (20.4 to 30.6$)$ & 27.5 (24.0 to 31.3$)$ \\
\hline
\end{tabular}

${ }^{*}$ Number of participants: numbers in brackets are weighted values as described in the text. Prevalence is given as point estimates with $95 \%$ Cls.

ADA, American Diabetes Association; AHA, American Heart Association; BMI, body mass index; $\mathrm{HbA}_{1 \mathrm{c}}$, hemoglobin $\mathrm{A}_{1 \mathrm{c}}$; IDF, International Diabetes Federation; NHLBI, National Heart, Lung, and Blood Institute; WHO, World Health Organization. 
BMI (men)

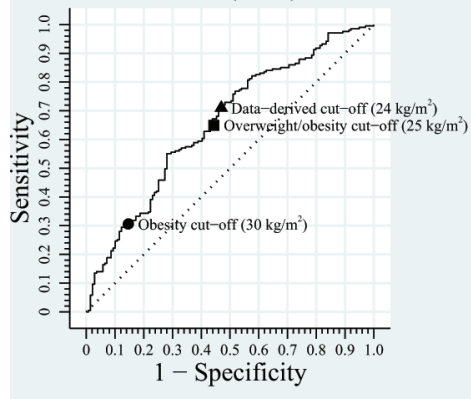

WC (men)

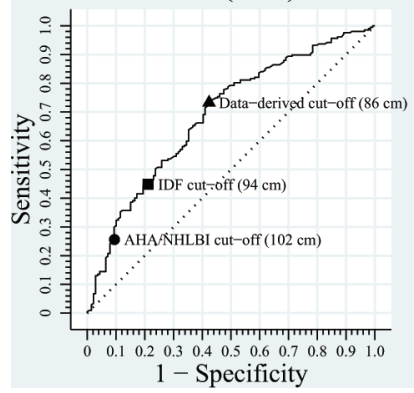

BMI (women)

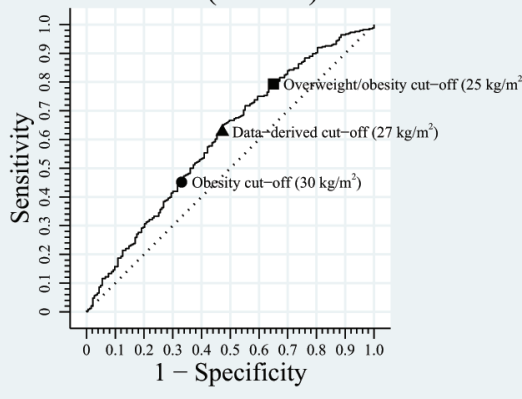

WC (women)

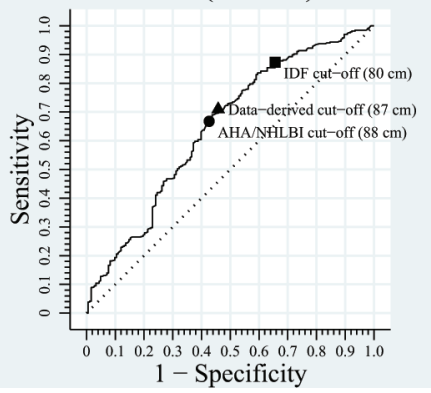

Figure 1 Receiver operating characteristic curves for hyperglycemia by BMI and WC. The positions of the data-derived cut points, standard BMI cut points and WC cut points of IDF and AHA/NHLBI are shown. AHA, American Heart Association; BMI, body mass index; IDF, International Diabetes Federation; NHLBI, National Heart, Lung, and Blood Institute; WC, waist circumference.

between the standard BMI cut-offs for overweight and obesity, with intermediate sensitivity and specificity and similar ability to discriminate between those with and without ADA-defined hyperglycemia. The data-derived cut-off for abdominal obesity in women (WC $\geq 87 \mathrm{~cm}$ ) approximated the AHA/NHLBI cut-off (WC $\geq 88 \mathrm{~cm}$ ) with, as expected, lower sensitivity but higher specificity than the IDF cut-off $(\mathrm{WC} \geq 80 \mathrm{~cm}$ ). Areas under the ROCs

Table 2 Characteristics of standard and data-derived BMl and waist cut-offs for detection of hyperglycemia, based on the American Diabetes Association categories

\begin{tabular}{|c|c|c|c|c|c|c|}
\hline & AUC & Sensitivity (\%) & Specificity (\%) & PPV (\%) & NPV (\%) & Youden index \\
\hline \multicolumn{7}{|l|}{$\mathrm{BMI} \geq 25 \mathrm{~kg} / \mathrm{m}^{2}$} \\
\hline Women & 57.1 (52.5 to 61.7$)$ & 79.0 (73.0 to 85.0$)$ & 35.0 (28.0 to 43.0$)$ & 68.0 (63.0 to 73.0$)$ & 49.0 (40.0 to 59.0$)$ & 0.14 \\
\hline Men & 59.4 (52.6 to 66.2$)$ & 64.0 (54.0 to 73.0$)$ & 54.0 (44.0 to 64.0$)$ & 63.0 (54.0 to 70.0$)$ & 56.0 (45.0 to 67.0$)$ & 0.19 \\
\hline \multicolumn{7}{|l|}{$\mathrm{BMI} \geq 30 \mathrm{~kg} / \mathrm{m}^{2}$} \\
\hline Women & 57.6 (52.3 to 63.0$)$ & 48.0 (42.0 to 54.0$)$ & $67.0(58.0$ to 75.0$)$ & $72.0(64.0$ to 78.0$)$ & 43.0 (36.0 to 49.0$)$ & 0.15 \\
\hline Men & 58.1 (52.4 to 63.8 ) & 30.0 (22.0 to 38.0$)$ & 86.0 (77.0 to 92.0$)$ & 72.0 (57.0 to 84.0 ) & 51.0 (42.0 to 59.0 ) & 0.16 \\
\hline \multicolumn{7}{|l|}{ BMI (data-derived) } \\
\hline Women $\left(\geq 27 \mathrm{~kg} / \mathrm{m}^{2}\right)$ & 57.8 (52.4 to 63.2$)$ & 63.0 (56.0 to 69.0$)$ & 53.0 (44.0 to 61.0$)$ & 70.0 (64.0 to 75.0$)$ & $45.0(37.0$ to 53.0$)$ & 0.16 \\
\hline $\operatorname{Men}\left(\geq 24 \mathrm{~kg} / \mathrm{m}^{2}\right)$ & 61.9 (55.9 to 67.8$)$ & 72.0 (64.0 to 79.0$)$ & 51.0 (41.0 to 61.0$)$ & 64.0 (56.0 to 71.0$)$ & 61.0 (50.0 to 71.0$)$ & 0.24 \\
\hline \multicolumn{7}{|l|}{ Abdominal obesity (IDF) } \\
\hline Women (WC $\geq 80 \mathrm{~cm}$ ) & 61.7 (57.3 to 66.1$)$ & 89.0 (84.0 to 92.0$)$ & 35.0 (27.0 to 44.0$)$ & 70.0 (66.0 to 74.0$)$ & $64.0(52.0$ to 74.0$)$ & 0.24 \\
\hline Men (WC $\geq 94 \mathrm{~cm}$ ) & 62.3 (55.9 to 68.8$)$ & 46.0 (37.0 to 56.0$)$ & 79.0 (67.0 to 87.0$)$ & $72.0(61.0$ to 81.0$)$ & 55.0 (45.0 to 64.0$)$ & 0.25 \\
\hline \multicolumn{7}{|c|}{ Abdominal obesity (AHA/NHLBI) } \\
\hline Women (WC $\geq 88 \mathrm{~cm}$ ) & 62.9 (57.6 to 68.2$)$ & $68.0(62.0$ to 74.0$)$ & 58.0 (50.0 to 65.0$)$ & 74.0 (68.0 to 79.0$)$ & 51.0 (43.0 to 59.0$)$ & 0.26 \\
\hline Men (WC $\geq 102 \mathrm{~cm})$ & 57.7 (52.8 to 62.7$)$ & 25.0 (18.0 to 33.0$)$ & 90.0 (83.0 to 95.0$)$ & 76.0 (59.0 to 87.0$)$ & 50.0 (42.0 to 58.0$)$ & 0.16 \\
\hline \multicolumn{7}{|c|}{ Abdominal obesity (data-derived) } \\
\hline Women $(\mathrm{WC} \geq 87 \mathrm{~cm}$ ) & 63.7 (58.3 to 69.1$)$ & 71.0 (65.0 to 77.0$)$ & 56.0 (47.0 to 64.0$)$ & 74.0 (68.0 to 79.0$)$ & 53.0 (44.0 to 61.0$)$ & 0.28 \\
\hline Men $(\mathrm{WC} \geq 86 \mathrm{~cm})$ & 66.2 (59.9 to 72.6 ) & 74.0 (65.0 to 81.0$)$ & 59.0 (48.0 to 69.0$)$ & 68.0 (60.0 to 75.0$)$ & 65.0 (54.0 to 76.0$)$ & 0.34 \\
\hline
\end{tabular}

Relevant findings using WHO categories of hyperglycemia are described in the text.

AHA, American Heart Association; AUC, area under the curve; BMI, body mass index; IDF, International Diabetes Federation; NHLBI, National Heart, Lung, and Blood Institute; NPV, negative predictive value; PPV, positive predictive value; WC, waist circumference. 
Table 3 Prevalence of generalized and abdominal obesity in women and men based on data-derived cut-offs for American Diabetes Association-defined hyperglycemia

\begin{tabular}{llll}
\hline & Women & Men & All \\
\hline Generalized obesity (\%) & $57.3(52.4$ to 62.1$)$ & $61.6(54.9$ to 68.0$)$ & $59.5(56.0$ to 62.8$)$ \\
Abdominal obesity (\%) & $61.5(56.1$ to 66.6$)$ & $58.9(51.6$ to 65.9) & $60.2(55.6$ to 64.7) \\
\hline
\end{tabular}

Figures are given as weighted percentages with $95 \%$ Cls.

were, however, similar for all three cut-offs. The CIs for the negative and positive predictive values for the standard cut-offs overlapped with those for the data-derived cut-offs for both BMI and WC.

For men, in contrast to women, the data-derived cut-off for BMI $\left(\geq 24 \mathrm{~kg} / \mathrm{m}^{2}\right)$ was closer to the standard cut-off for overweight than to the cut-off for generalized obesity. As expected, the lower values were more sensitive but less specific and had similar ability to standard cut-offs in discriminating between those with and without hyperglycemia. The data-derived WC cut-off in men was $86 \mathrm{~cm}$, lower than both the IDF cut-off of $94 \mathrm{~cm}$ and the AHA/ NHLBI cut-off of $102 \mathrm{~cm}$, with a higher negative predictive value than either standard cut-off but no clear difference in positive predictive value.

Similar anthropometric cut-offs were obtained when repeating the analyses using the WHO criteria for hyperglycemia. In women, the data-derived BMI cut-off was $29 \mathrm{~kg} / \mathrm{m}^{2}$, with a Youden index of 0.20 , and in men it was $23 \mathrm{~kg} / \mathrm{m}^{2}$ (Youden 0.24 ). In women, the WC cut-off was $87 \mathrm{~cm}$, similar to that obtained using ADA-defined hyperglycemia (Youden 0.31), while in men it was $88 \mathrm{~cm}$ (Youden 0.35). AUC, sensitivity and specificity for BMI and WC cut-offs for detecting WHO-defined hyperglycemia were similar to those for detecting ADA-defined hyperglycemia. As would be expected, given the lower prevalence of WHO-defined hyperglycemia, the positive predictive values for these data-derived indices were lower and the negative predictive values higher than with ADA-defined hyperglycemia. The WC cut-off of $86 \mathrm{~cm}$ in men, for example, had a positive predictive value for WHO-defined hyperglycemia of $35.9 \%$ (95\% CI 28.6 to 42.8 ), while the negative predictive value was $90.1 \%$ (95\% CI 83.0 to 94.5$)$.

In contrast to standard cut-offs, the use of data-derived cut-offs resulted in similar prevalence of generalized and abdominal obesity in men and women, as shown in table 3. Irrespective of the criterion used, individuals above the obesity cut-offs had a higher age-adjusted prevalence of ADA-defined hyperglycemia than those below (table 4). Prevalence ratios for BMI cut-offs in women ranged between 1.2 and 1.3, while those for WC were between 1.4 and 1.8. In men, there was $30 \%-50 \%$ higher prevalence of hyperglycemia in those above the BMI thresholds and 30\%-70\% higher prevalence in those above the WC thresholds. Prevalence ratios were even higher when the more conservative WHO definition of hyperglycemia was used.

\section{DISCUSSION}

Undiagnosed diabetes and pre-diabetes are prevalent in the Caribbean island of Barbados, where between a quarter and a half of adults in our survey were found to be hyperglycemic, depending on the definition used. In women, population-specific BMI and WC cut-offs were similar to existing cut-offs, with comparable performance in discriminating between those with and without hyperglycemia, whereas in men the data-derived cut-offs for both BMI and WC were lower than the standard cutoffs, with the WC cut-off having better negative predicative value than standard values. Use of lower cut-offs in men more than doubled the prevalence of obesity, with a higher prevalence ratio of hyperglycemia in men above the data-derived WC cut-off than in those above standard WC cut-offs.

Table 4 Age-adjusted prevalence ratios for hyperglycemia defined by ADA and WHO using standard and data-derived cut-offs for generalized and abdominal obesity

\begin{tabular}{|c|c|c|}
\hline & \multicolumn{2}{|c|}{ Prevalence ratio $(95 \% \mathrm{Cl})$} \\
\hline & Women & Men \\
\hline \multicolumn{3}{|l|}{ Generalized obesity } \\
\hline \multicolumn{3}{|l|}{$\mathrm{BMI} \geq 25 \mathrm{~kg} / \mathrm{m}^{2}$} \\
\hline ADA-defined hyperglycemia & $1.3(1.1$ to 1.6$)$ & $1.3(1.0$ to 1.7$)$ \\
\hline WHO-defined hyperglycemia & 1.9 (1.3 to 2.9$)$ & 1.5 (0.9 to 2.4$)$ \\
\hline \multicolumn{3}{|l|}{$\mathrm{BMI} \geq 30 \mathrm{~kg} / \mathrm{m}^{2}$} \\
\hline ADA-defined hyperglycemia & $1.2(1.0$ to 1.4$)$ & $1.4(1.2$ to 1.7$)$ \\
\hline WHO-defined hyperglycemia & 1.7 (1.2 to 2.2$)$ & 1.6 (1.1 to 2.2$)$ \\
\hline \multicolumn{3}{|l|}{ Data-derived } \\
\hline ADA-defined hyperglycemia & $1.2(1.1$ to 1.4$)$ & 1.5 (1.1 to 1.9$)$ \\
\hline WHO-defined hyperglycemia & 1.7 (1.3 to 2.3$)$ & $1.8(1.1$ to 3.1$)$ \\
\hline \multicolumn{3}{|l|}{ Abdominal obesity } \\
\hline \multicolumn{3}{|l|}{ IDF criteria } \\
\hline ADA-defined hyperglycemia & 1.8 (1.3 to 2.4$)$ & $1.4(1.1$ to 1.7$)$ \\
\hline WHO-defined hyperglycemia & 2.9 (1.6 to 5.2$)$ & 1.6 (1.1 to 2.3$)$ \\
\hline \multicolumn{3}{|l|}{ AHA/NHLBI criteria } \\
\hline ADA-defined hyperglycemia & $1.4(1.2$ to 1.7$)$ & 1.3 (1.1 to 1.7$)$ \\
\hline WHO-defined hyperglycemia & 2.4 (1.5 to 3.6$)$ & 1.6 (1.1 to 2.4$)$ \\
\hline \multicolumn{3}{|l|}{ Data-derived } \\
\hline ADA-defined hyperglycemia & 1.5 (1.2 to 1.8$)$ & 1.7 (1.2 to 2.3$)$ \\
\hline WHO-defined hyperglycemia & 2.8 (1.9 to 4.2$)$ & 2.7 (1.6 to 4.5$)$ \\
\hline
\end{tabular}

ADA, American Diabetes Association; AHA, American Heart Association; $\mathrm{BMI}$, body mass index; IDF, International Diabetes Federation; NHLBI, National Heart, Lung, and Blood Institute; WHO, World Health Organization. 
Previous studies have highlighted the need for ethnicity-specific anthropometric cut-offs in identifying Afro-Caribbean people at risk of hyperglycemia. An ageadjusted and sex-adjusted BMI cut-off of $27.2 \mathrm{~kg} / \mathrm{m}^{2}$ in Afro-Caribbean individuals living in the UK was associated with a diabetes incidence rate, after a median follow-up of 19 years, equivalent to a BMI of $30 \mathrm{~kg} / \mathrm{m}^{2}$ in Europeans, while WC of $81.2 \mathrm{~cm}$ in Afro-Caribbean women and $90.4 \mathrm{~cm}$ in Afro-Caribbean men was associated with age-adjusted incidence rates of diabetes similar to those in Europeans with WC of $88 \mathrm{~cm}$ and $102 \mathrm{~cm}$ in men and women, respectively. ${ }^{19}$ In a longitudinal study in Jamaica, BMI cut-offs of $29.3 \mathrm{~kg} / \mathrm{m}^{2}$ in women and $24.8 \mathrm{~kg} / \mathrm{m}^{2}$ in men and WC cut-offs of $84.5 \mathrm{~cm}$ in women and $88 \mathrm{~cm}$ in men were optimal in predicting incident diabetes during a mean 4 -year follow-up. ${ }^{20}$ These studies suggest that while standard BMI and WC cut-offs may be appropriate in women, they may be less applicable in men, who may have a higher risk of hyperglycemia at a lower degree of adiposity. The reasons for these ethnic differences remain unclear, however. Visceral fat, for example, may be implicated in the pathogenesis of type 2 diabetes, but appears to be lower in Afro-Caribbean individuals compared with those of European descent, ${ }^{21}$ despite the higher risk of hyperglycemia. Factors other than adipose tissue distribution and function may therefore play a significant role in the development of hyperglycemia in individuals of African descent. ${ }^{22}$ Interestingly, the UK study, unlike our study and the work conducted in Jamaica, did not find a sex difference in optimal BMI, but this may be attributable to potential differences in Afro-Caribbean migrants when compared with Afro-Caribbean populations in the Caribbean. Our study complements this longitudinal work by identifying cut-offs that can be used to identify individuals at risk of prevalent hyperglycemia who would benefit from further clinical investigation.

Our study provides further data to support the use of population-derived cut-offs to define both generalized and abdominal obesity. Work in sub-Saharan African populations, although investigating metabolic risk, also highlighted the need for population-specific cut-offs. ${ }^{9}$ Such cut-offs, in addition to identifying individuals at risk, could also inform public health messaging on appropriate BMI and WC thresholds in Afro-Caribbean populations, who are at high risk of developing diabetes and diabetes-related complications. The use of lower cutoffs in men would, however, increase the prevalence of obesity and in turn increase the number of individuals identified for hyperglycemia screening with the associated costs. This additional cost to the healthcare system needs to be weighed against the advantages of the lower diabetes morbidity and mortality that could result from earlier detection and intervention.

Our study does have limitations. Our sample size was small, which was reflected in the broad and overlapping CIs. The survey response rate was $55 \%,{ }^{11}$ and while somewhat low, this is comparable with similar surveys in high-income countries, with the National Health and Nutrition Examination
Survey in the USA reporting an unweighted response rate of $48.8 \%$ for completion of the interview and examination in 2017-2018 ${ }^{23}$ and the Health Survey for England reporting a response rate of $55 \%$ in adults in $2017 .{ }^{24}$ We did, however, apply sample weights to ensure the sample was more representative of the background population. Given that ADA and $\mathrm{WHO}$ guidelines promote use of $\mathrm{HbA}_{1 c}$ to identify hyperglycemia, we included it in our definition, but this may have overestimated the prevalence of hyperglycemia in our sample as current $\mathrm{HbA}_{1 \mathrm{c}}$ thresholds may overdiagnose hyperglycemia in populations of African ancestry. ${ }^{14}$ Due to our sample size, we were unable to investigate whether the relationship between anthropometric measures and hyperglycemia varies with age. Despite these limitations, our study, which is to our knowledge one of the first in the Caribbean, adds to the growing literature on appropriate anthropometric cut points in Afro-Caribbean populations.

In conclusion, optimal BMI and WC cut-offs for discriminating between Afro-Caribbean individuals with and without hyperglycemia appear, in men, to be lower than internationally accepted cut-offs. Validation of our data-derived cut-offs through replication of our findings in a new data set is, however, necessary.

\section{Author affiliations}

${ }^{1}$ MRC/Wits Rural Public Health and Health Transitions Research Unit, School of Public Health, University of the Witwatersrand Faculty of Health Sciences, Johannesburg, South Africa

${ }^{2}$ The University of the West Indies George Alleyne Chronic Disease Research Centre, Bridgetown, Barbados

${ }^{3}$ Faculty of Medical Sciences, The University of the West Indies Cave Hill Campus, Bridgetown, Barbados

${ }^{4}$ Epidemiology Department, Epiconcept SAS, Paris, France

${ }^{5}$ European Centre for Environment and Human Health, University of Exeter Medical School, Exeter, UK

${ }^{6}$ MRC Epidemiology Unit, University of Cambridge School of Clinical Medicine, Cambridge, UK

Acknowledgements We acknowledge the drive and intellectual contribution of the late $\mathrm{Dr}$ Charles Taylor to the early discussions on the value of examining anthropometric cut-offs as markers of cardiovascular risk in these data. We also gratefully acknowledge those who assisted in recruiting participants, the team of data collectors, data entry staff and all the study participants.

Contributors $\mathrm{CH}, \mathrm{IRH}, \mathrm{AJMH}, \mathrm{AMCR}$ and $\mathrm{NU}$ conceived and designed the survey and supervised the data collection. NU performed the statistical analysis. ANW and NU wrote the first draft of the manuscript. All authors critically revised the manuscript and approved the final version. All authors agree to be accountable for all aspects of the work.

Funding The project was supported by the Ministry of Health of the Government of Barbados. ANW is supported by the Fogarty International Center of the National Institutes of Health under Award Number K43TW010698. This paper describes the views of the authors and does not necessarily represent the official views of the National Institutes of Health (USA).

Disclaimer One of the authors (AJMH) joined the Pan American Health Organization (PAHO) after this work was undertaken. This manuscript was written independently of his work with the organization and does not represent the views of the PAHO.

Competing interests None declared.

Patient consent for publication Not required.

Ethics approval The Ministry of Health of the Government of Barbados reviewed and approved the study design. The survey was approved by the Research Ethics Committee of the University of the West Indies, Cave Hill and the Barbados Ministry of Health. The conduct of the study adhered to the principles of the Declaration of Helsinki. 
Provenance and peer review Not commissioned; externally peer reviewed.

Data availability statement № data are available.

Open access This is an open access article distributed in accordance with the Creative Commons Attribution Non Commercial (CC BY-NC 4.0) license, which permits others to distribute, remix, adapt, build upon this work non-commercially, and license their derivative works on different terms, provided the original work is properly cited, appropriate credit is given, any changes made indicated, and the use is non-commercial. See: http://creativecommons.org/licenses/by-nc/4.0/.

ORCID iD

Alisha N Wade http://orcid.org/0000-0002-1158-2523

\section{REFERENCES}

1 GBD 2016 Causes of Death Collaborators. Global, regional, and national age-sex specific mortality for 264 causes of death, 19802016: a systematic analysis for the global burden of disease study 2016. Lancet 2017:390:1151-210.

2 GBD 2016 DALYs and HALE Collaborators. Global, regional, and national disability-adjusted life-years (DALYs) for 333 diseases and injuries and healthy life expectancy (HALE) for 195 countries and territories, 1990-2016: a systematic analysis for the global burden of disease study 2016. Lancet 2017;390:1260-344.

3 Pan American Health Organisation/World Health Organisation. Evidence and intelligence for action in health/ health analysis, metrics and evidence. health situation in the Americas: core indicators 2018. Washington D.C., USA, 2018.

4 World Health Organisation. Diagnosis and management of type 2 diabetes (HEARTS-D). Geneva, 2020.

5 Abdulkadri AO, Cunningham-Myrie CA, Forrester T. Economic burden of diabetes and hypertension in CARICOM states. Social and Economic Studies 2009;58:175-97.

6 Rose G. Sick individuals and sick populations. Int J Epidemiol 2001;30:427-32.

7 Cooney M-T, Dudina A, Whincup P, et al. Re-evaluating the rose approach: comparative benefits of the population and high-risk preventive strategies. Eur J Cardiovasc Prev Rehabil 2009;16:541-9.

8 Ntuk UE, Gill JMR, Mackay DF, et al. Ethnic-Specific obesity cutoffs for diabetes risk: cross-sectional study of 490,288 UK Biobank participants. Diabetes Care 2014;37:2500-7.

9 Ekoru K, Murphy GAV, Young EH, et al. Deriving an optimal threshold of waist circumference for detecting cardiometabolic risk in subSaharan Africa. Int J Obes 2018;42:487-94.

10 Hara K, Matsushita Y, Horikoshi M, et al. A proposal for the cutoff point of waist circumference for the diagnosis of metabolic syndrome in the Japanese population. Diabetes Care 2006;29:1123-4.
11 Howitt C, Hambleton IR, Rose AMC, et al. Social distribution of diabetes, hypertension and related risk factors in Barbados: a crosssectional study. BMJ Open 2015;5:e008869.

12 Adams OP, Herbert JR, Howitt C, et al. The prevalence of peripheral neuropathy severe enough to cause a loss of protective sensation in a population-based sample of people with known and newly detected diabetes in Barbados: a cross-sectional study. Diabet Med 2019;36:1629-36.

13 Leske MC, Wu S-Y, Hennis A, et al. Hyperglycemia, blood pressure, and the 9-year incidence of diabetic retinopathy: the Barbados eye studies. Ophthalmology 2005;112:799-805.

14 Unwin N, Howitt C, Rose AM, et al. Prevalence and phenotype of diabetes and prediabetes using fasting glucose vs $\mathrm{HbA} 1 \mathrm{c}$ in a Caribbean population. J Glob Health 2017;7:020407.

15 PanAmerican steps instrument and supporting material. Pan American health organisation. Available: https://www.paho.org/ hq/index.php?option=com_content\&view=article\&id=1929:2009panamerican-steps-instrument-supporting-material\&ltemid=1668\& lang=en [Accessed 28 Jan 2020].

16 Alberti KGMM, Zimmet P, Shaw J, et al. The metabolic syndrome--a new worldwide definition. Lancet 2005;366:1059-62.

17 Grundy SM, Cleeman JI, Daniels SR, et al. Diagnosis and management of the metabolic syndrome: an American heart Association/National heart, lung, and blood Institute scientific statement. Circulation 2005;112:2735-52.

18 American Diabetes Association. 2. Classification and Diagnosis of Diabetes: Standards of Medical Care in Diabetes-2019. Diabetes Care 2019;42:S13-28.

19 Tillin T, Sattar N, Godsland IF, et al. Ethnicity-specific obesity cutpoints in the development of Type 2 diabetes - a prospective study including three ethnic groups in the United Kingdom. Diabet Med 2015;32:226-34.

20 Sargeant LA, Bennett Fl, Forrester TE, et al. Predicting incident diabetes in Jamaica: the role of anthropometry. Obes Res 2002;10:792-8.

21 Eastwood SV, Tillin T, Wright A, et al. Estimation of CT-derived abdominal visceral and subcutaneous adipose tissue depots from anthropometry in Europeans, South Asians and African Caribbeans. PLoS One 2013;8:e75085.

22 Ladwa M, Bello O, Hakim O, et al. Ethnic differences in beta cell function occur independently of insulin sensitivity and pancreatic fat in black and white men. BMJ Open Diabetes Res Care 2021;9:e002034.

23 Unweighted response rates for NHANES 2017-2018 by age and gender. National center for health statistics. Available: https://wwwn. Cdc.Gov/nchs/data/nhanes3/responserates/nhanes-2017-2018response-rates-508.Pdf [Accessed 2 Mar 2020]

24 Health survey for England 2017: quick guide. NatCen social research and UCL. Available: http://healthsurvey.Hscic.Gov.Uk/media/78596/ hse17-quick-guide-rep.Pdf [Accessed 2 Mar 2020]. 